\title{
LA OFERTA DEL NUEVO ESTADO. PROPAGANDA E IDEOLOGIZACIÓN DEL COMBATIENTE SUBLEVADO EN LA GUERRA CIVIL ESPAÑOLA (1936-1939)'
}

The offer by the new State. Propaganda and indoctrination of the rebel soldier in the Spanish Civil War (1936-1939)

\author{
MIGUEL ALONSO IBARRA \\ Universitat Autònoma de Barcelona \\ miguel.alonso.ibarra@gmail.com
}

Cómo citar/Citation

Alonso Ibarra, M. (2020).

La oferta del Nuevo Estado. Propaganda e ideologización del combatiente sublevado en la guerra civil española (1936-1939)

Historia y Política, 44, 305-335

doi: https://doi.org/10.18042/hp.44.11

(Recepción: 30/10/2019; evaluación: 24/12/2019; aceptación: 12/02/2020; publicación: 27/11/2020)

\section{Resumen}

En los últimos años, la historiografía ha abordado el proceso constructivo del régimen franquista a través del estudio de la experiencia bélica de los combatientes sublevados durante la guerra civil espańola (1936-1939). Esto ha conducido a dos interpretaciones fundamentales: que la principal función del Ejército fue eminentemente coercitiva, y que el adoctrinamiento estaba subordinado a ella. Consecuentemente, no se dio una experiencia de ideologización significativa entre los combatientes rebeldes. Partiendo de este marco, el artículo busca cuestionar ambas ideas,

1 El autor participa del Proyecto de I+D "Posguerras civiles: violencia y (re)construcción nacional en España y Europa, 1939-49” (PGC2018-097724-B-I00) del MCIU, dirigido por Javier Rodrigo Sánchez 
sosteniendo que sí existió un proceso de ideologización de los soldados sublevados en el que además el Ejército tuvo un papel crucial, lo que permite reconsiderar la relevancia de sus políticas de adoctrinamiento. A través de un análisis de la documentación militar referida a estas políticas, tanto a nivel general como descendiendo a casos divisionales específicos, e incorporando también la perspectiva de los propios combatientes a través de sus diarios de guerra, se ahondará en las formas y temas de dicha propaganda, argumentando que fue la vía pragmática, más que la ideológica, la que favoreció la atracción de los combatientes hacia el nuevo Estado. Un enfoque que permitiría entender cómo se construyeron los apoyos sociales a la dictadura entre el colectivo de los excombatientes, y en general en el conjunto de la sociedad española.

\title{
Palabras clave
}

Combatientes; experiencia bélica; ideologización; Guerra Civil española; apoyos sociales al franquismo.

\begin{abstract}
In recent years, historiography has addressed the building process of the Francoist regime through the analysis of the war experience of Rebel soldiers during the Spanish Civil War (1936-1939). This has produced two main interpretations: that coercion was the primary role played by the army, being the indoctrination significantly subordinated to it. And, consequently, that a relevant ideologisation experience among Rebel soldiers didn't take place. From this frame, the article aims to question these two ideas, arguing that there was indeed a process of ideologisation of Rebel soldiers in which, moreover, the army played a crucial role. Therefore, this allows to rethink the importance of the army's indoctrination policies. By analysing military sources concerning these policies at a general and divisional level, and incorporating soldiers' perspectives through their war diaries, I will delve into the forms and topics of this propaganda, arguing that the pragmatic approach, more than the ideological one, was ultimately what attracted combatants to the New State. Moreover, this interpretation would allow to understand how social support towards the dictatorship was built among war veterans, and more generally among the whole Spanish society.
\end{abstract}

\section{Keywords}

War experience; combatants; indoctrination; Spanish Civil war; Francoist social support. 
I. INTRODUCCIÓN. II. LA ESTRUCTURA DE LA PROPAGANDA EN EL EJÉRCITO REBELDE. III. INSTRUCCIÓN MILITAR Y FORMACIÓN IDEOLÓGICA. LA EDUCACIÓN MORAL DEL SOLDADO. IV. COLONIZAR EL OCIO Y EL TEDIO. PRENSA Y LECTURAS COMO VECTORES DE PROPAGANDA. V. CONCLUSIÓN. BIBLIOGRAFIA.

\section{INTRODUCCIÓN}

En las últimas dos décadas, se han producido avances significativos en torno a una cuestión capital para entender cómo se construyó el régimen franquista: la experiencia bélica de los combatientes sublevados durante la guerra civil española (1936-1939). Este colectivo, compuesto por 1,2 millones de hombres, se convirtió en un apoyo esencial del franquismo ${ }^{2}$, lo que apuntaría a un proceso de socialización ideológica asociado y facilitado por la movilización bélica. Sin embargo, buena parte de la historiografía ha sugerido que el paso por las filas del Ejército sublevado no comportó una ideologización significativa de los combatientes y que la conscripción fue esencialmente coercitiva, con un componente adoctrinador débil y subordinado ${ }^{3}$. A mi juicio, ambos planteamientos parten de una comprensión maximalista de lo ideológico, entendido en términos absolutos. Por el contrario, el presente artículo plantea la movilización bélica como un proceso de socialización ideológica con un importante componente constructivo desde abajo, es decir, desde la disección y adaptación de los discursos por parte de los individuos, quienes adoptan, critican o rechazan los elementos componentes de dichos discursos en función de sus propios intereses y realidades particulares. Esto obligaba al bando rebelde a plantear una oferta a aquellos a los que quería convencer, y al mismo tiempo confería un papel activo a los receptores de dicha oferta, esto es los combatientes, y por extensión el conjunto de la sociedad española. A nivel conceptual, dicho enfoque permite situar la cotidianidad como el marco idóneo en el que observar los éxitos, fracasos y límites del mencionado proceso de socialización ideológica, conectado así con toda una serie de estudios que

Alcalde (2014): 46.

3 Matthews (2012) y Leira-Castiñeira (2018). 
han interpretado los apoyos sociales a las dictaduras fascistas desde perspectivas similares ${ }^{4}$.

De igual modo, el objeto de estudio analizado y el enfoque adoptado entroncan directamente con los debates historiográficos sobre el modo en que se cimentó el régimen franquista, así como con los límites del proyecto político impulsado por el nuevo Estado, dos elementos con los que el artículo tiene el propósito de dialogar. El otorgamiento de beneficios particulares como mecanismo de incorporación de diversos colectivos y grupos sociopolíticos a la dictadura ha sido una cuestión ampliamente abordada por la historiografía, si bien no lo ha sido tanto en el contexto constructivo del franquismo, es decir, la Guerra Civil'5. Así, el análisis de esos mecanismos aplicados por el Ejército sublevado sobre el conjunto de su masa combatiente busca entender cómo el régimen pudo incorporar a su proyecto a colectivos tan heterogéneos, ahondando en lo concreto de su oferta. El combatiente resulta aquí especialmente relevante, considerando además el contraste existente entre la función que desempeñó su figura en la posguerra en tanto que pilar legitimador del régimen, y la diversidad de actitudes del conjunto del colectivo hacia el franquismo $^{6}$. Con ello, el artículo pretende contribuir también a la reconsideración de la narrativa del fracaso y la desmovilización planteada por amplios sectores historiográficos a través de dos variables: la participación política y la posguerra?

En este marco, el artículo busca cuestionar ese paradigma de los dos fracasos -ideologización en guerra y apoyo en posguerra - y defender la existencia de un proceso de socialización ideológica, mucho más pragmática que política, de la masa combatiente vehiculado esencialmente a través de su encuadramiento en el Ejército. Una socialización que habría contribuido a

4 Para el caso español, véase Rodríguez Barreira (2013). Para la Italia fascista, centrado en el ejemplo de la ciudad de Venecia, Ferris (2012). Sobre Alemania, Gellately (2001): por ejemplo, 257-259. Acerca del Japón imperial antes y durante la Segunda Guerra Mundial, Yoshiaki (2015): por ejemplo, 44-46.

5 Algo que, de hecho, ya señalaba Rodrigo (2013: 51). Sobre los apoyos sociales véanse Molinero (2006); Del Arco (2007a); Cobo et al. (2011), y Hernández Burgos (2011). Más específicamente sobre el otorgamiento de puestos a individuos procedentes de entre los apoyos sociales al golpe, incluidos excombatientes, véanse Morente (2001); Sanz (2004), o Del Arco (2007b).

6 El excombatiente como figura clave de la posguerra en Alcalde (2013). La falta general de afinidad de los veteranos con el régimen ha sido sugerida por Leira-Castiñeira (2018: 423-464).

7 Respectivamente, entre otros, Rodríguez Barreira (2014) o Vincent (2006). 
que los futuros excombatientes se convirtiesen en un pilar importante de la dictadura. Mediante un análisis de las directivas y órdenes específicas que dieron forma al entramado de instrucción y propaganda construido por el bando rebelde, y especialmente por sus fuerzas armadas, el objetivo es sugerir que el Ejército desempeñó una doble función durante la guerra: obtener la victoria en el campo de batalla y convertir a esos 1,2 millones de individuos movilizados en apoyos sociales del nuevo Estado, dos roles implementados activa y complementariamente. Para ello, analizaré las formas y contenidos específicos de dicha propaganda, poniéndolos en relación con las perspectivas y preocupaciones de los combatientes a través de la incorporación de memorias y diarios de guerra. Así, este artículo defiende que la experiencia bélica fue, también, una experiencia de ideologización. No obstante, esa ideologización debe entenderse como la construcción de espacios de aquiescencia y apoyo al franquismo sobre la base de contrapartidas pragmáticas que, además, codificaban una serie de elementos ideológicos nucleares de la cultura política del régimen, aunque planteados rudimentariamente ${ }^{8}$. En última instancia, la relevancia de los excombatientes como elemento de legitimación y apoyo de la dictadura, aun con sus muchos matices, permite ponderar el alcance de un proceso de socialización ideológica que, empero, tuvo sus límites evidentes.

\section{LA ESTRUCTURA DE LA PROPAGANDA EN EL EJÉRCITO REBELDE}

La movilización de masas decretada por el bando sublevado tenía tres objetivos fundamentales: la incorporación al Ejército de los cientos de miles de individuos necesarios para librar una guerra total; el encuadramiento de amplias capas sociales, que dada su heterogeneidad incluían grupos no afines a la insurrección, lo que permitió su control en el seno de una institución fuertemente coercitiva como eran las Fuerzas Armadas; y la socialización ideológica de toda una serie de ideas fuerza para generar apoyos al proyecto político rebelde entre la masa combatiente. Los dirigentes sublevados eran conscientes de que la guerra constituía el escenario constructivo del nuevo Estado, lo que hacía del encuadramiento castrense de 1,2 millones de individuos una oportunidad ideal para comenzar a cimentar las bases de la futura dictadura mediante el adoctrinamiento y la propaganda?. Así, el Ejército puso en marcha diversas iniciativas

8 La concreción de esas recompensas en la posguerra en Hernández Burgos (2016b: 126-132).

9 Un objetivo que también se enfocó hacia la retaguardia a través de iniciativas como el Auxilio Social o Radio Nacional de España, que ejercían su función en ambos 
destinadas a abarcar el mayor número de ámbitos posibles de la vida del soldado: desde la propia instrucción militar al tiempo de ocio y tedio en la trinchera, pasando por la preocupación por la familia o la desmovilización de posguerra.

Por una parte, el control que tenía el Ejército sobre la totalidad del proceso de movilización, desde el adiestramiento inicial hasta el despliegue de los soldados, le permitió emplear la necesaria formación militar que recibían los reclutas para tareas de adoctrinamiento y propaganda, a través de la denominada «educación moral del soldado». Esta combinaba la inculcación de valores castrenses - deber, amor a la patria, sacrificio - con la explicación de contenidos netamente ideológicos - los principios del Movimiento, Franco como líder carismático-, sin olvidar que dichos valores castrenses tenían una indudable orientación ideológica. Es decir, que la sublevación, también en lo ideológico, no podía entenderse sin el Ejército, y la voluntad castrense de convencer y adoctrinar no podía comprenderse sin su propia ideologización en los años previos a la insurrección ${ }^{10}$.

Por otra, FET y de las JONS tuvo su propio órgano, la Delegación Nacional de Prensa y Propaganda (DNPP), creada en mayo de 1937 bajo la dirección del sacerdote navarro Fermín Yzurdiaga ${ }^{11}$. La tarea de la DNPP en el frente consistió en la elaboración de directrices propagandísticas, la publicación de folletos y la organización de diversos servicios de lectura para los soldados. El objetivo era informarles sobre las razones que habían llevado a la guerra - con especial incidencia en los crímenes cometidos por los republicanos antes y durante el conflicto-, delinear los modelos organizativos de la nueva España victoriosa, y explicar el papel de los combatientes en la posguerra. Además de la propaganda directa, iniciativas de la DNPP como el envío de libros buscaban aprovechar los espacios de ocio y tedio de la vida en el frente, con la idea de que los soldados recurriesen a estas lecturas, muy orientadas ideológicamente, como entretenimiento. No obstante, los testimonios de los propios combatientes ponían de manifiesto el reducido interés en dichas temáticas. El capellán legionario José Caballero se quejaba amargamente de que, en su ausencia, las trincheras eran pasto del «vino, juego y carne [prostitutas]». De hecho, a la hora de repartir «[...] catecismos y libros piadosos» entre los soldados siempre incluía tabaco para intentar favorecer la recepción de unas lecturas que, aparentemente, no suscitaban demasiado entusiasmo ${ }^{12}$.

espacios simultáneamente. Véanse Cenarro (2005) o Pizarroso Quintero (2005).

10 Jensen (2014).

11 Los organismos de propaganda rebeldes en Núñez de Prado y Clavell (1992): 305-339, y Pizarroso Quintero y Sapag (2012): 21-54.

12 Caballero (1976): 64 y 297. 
Sin ir más lejos, el combatiente Manuel Alfredo Paz afirmaba que el mejor mecanismo para abstenerse de la realidad del frente eran los naipes: «[...] la guerra no existe para nosotros y la gran tragedia de España no nos interesa $»^{13}$. Los soldados preferían dedicar su tiempo libre a los juegos de azar o a leer la prensa diaria, en vez de a bucear por sesudas disquisiciones acerca de la necesaria implicación de los intelectuales católicos en la Cruzada como las que podían aparecer en la revista Jerarquía, una de las que les eran enviadas ${ }^{14}$.

Por ello, otro de los grandes vectores de adoctrinamiento de la tropa fue la prensa, cuya censura y contenidos también se canalizaron a través de la DNPP ${ }^{15}$. Los periódicos constituían un elemento esencial en la vida del soldado: informaban de las operaciones militares, de asuntos políticos relacionados con la guerra o de cuestiones triviales como el fútbol, que servían como distracción. Pero, fundamentalmente, les permitían conocer el estado de la retaguardia y saber de sus seres queridos, ya que la marcha de los hombres jóvenes al frente dejaba a muchas familias en una situación de precariedad e indefensión, algo por lo que siempre intentaron velar los combatientes ${ }^{16}$. El reparto de periódicos se esperaba con avidez en las trincheras, pues era una de las pocas vías, junto con la correspondencia, para saber qué sucedía en sus lugares de origen o qué había pasado con parientes y amigos. Tal y como apuntaba el combatiente José Llordés, «[...] volví a sentirme contento porque los nacionales se iban acercando a mi pueblo» ${ }^{17}$. De hecho, muchos casos de deserción en ambos bandos estuvieron motivados por la necesidad de visitar a los familiares por diversos motivos $^{18}$. Por ello, los propagandistas del bando rebelde explotaron en beneficio propio el ocio en las trincheras y la necesidad que tenían los soldados de recibir noticias de la retaguardia, mediante un estricto control y una orientación ideológica de los contenidos que se publicaban en la prensa.

Para conseguir una mayor influencia de la propaganda, el Ejército y la DNPP adecuaron sus contenidos y lenguajes a la realidad y las preocupaciones concretas de los soldados, en vez de simplemente intentar socializar un discurso abstracto con escasa incidencia sobre la cotidianidad de estos individuos. Por un lado, se adaptó el discurso para que pudiera ser comprendido e interiorizado por

13 Paz Fernández (1973): 46.

14 «Sermón de la Tarea Nueva. Mensaje a los intelectuales católicos», por Laín Entralgo (2011): 75-90.

15 Sobre la prensa durante la Guerra Civil véanse Núñez de Prado y Clavell (1992):

77-112, o González Calleja (2012)

16 Hernández Burgos (2016a): 452-453.

17 Llordés (1968): 192.

18 Corral (2006). 
una población en su mayoría carente de estudios medios o superiores, o directamente analfabeta. Era inútil, tomando nuevamente como ejemplo el artículo aparecido en Jerarquía, hablar de la "[...] brutal rebeldía nihilista y oriental» para describir al enemigo republicano si el soldado no entendía palabras como «nihilista», el sentido con el que se usaba el término «oriental», o sencillamente a qué se estaba refiriendo el autor del texto ${ }^{19}$. La simplificación del lenguaje ampliaba el número de destinatarios de la propaganda y facilitaba la comprensión de los elementos clave de la ideología del bando rebelde. No se trataba, por ende, de hacer que los combatientes entendiesen las complejidades de la cultura política fascista, sino proveerles de un sencillo marco de referencia ideologizado en el que insertar sus preocupaciones cotidianas ${ }^{20}$.

La propaganda buscó incorporar al nuevo Estado a cuantos más individuos fuese posible mediante una orientación pragmática de los temas abordados. Más allá de charlas y folletos teóricos de contenido ideológico, el Ejército se esforzó por explicar a los combatientes los beneficios que comportaba la adhesión a su proyecto. Mediante la promesa de unas contraprestaciones vinculadas a su condición de combatientes y de las que también se beneficiarían sus familias, el objetivo era fomentar su voluntad de combatir y ganarse su apoyo una vez acabada la guerra. Por ejemplo, durante la contienda se pensionó a las esposas e hijos de los soldados en servicio, ayudas económicas que se extenderían tras el triunfo de las armas rebeldes ${ }^{21}$. Además, este tipo de enfoques propagandísticos buscaban potenciar la fidelidad hacia la dictadura y la figura de Franco como condiciones imprescindibles para la obtención de esos beneficios, lo que ayudaba a socializar algunos de los componentes ideológicos esenciales de la cultura política del nuevo Estado. En definitiva, lo que se pretendía era comprar el apoyo, o al menos la aquiescencia, de la masa combatiente a través de una serie de medidas que abordaban sus preocupaciones reales y que eran mucho más concretas que la retórica político-ideológica, por mucho que esta estuviera también presente como elemento subyacente.

\section{INSTRUCCIÓN MILITAR Y FORMACIÓN IDEOLÓGICA. LA EDUCACIÓN MORAL DEL SOLDADO}

Una de las principales tareas del Ejército fue la instrucción de los individuos movilizados durante toda la contienda. Los combatientes estuvieron

19 Laín Entralgo (2011): 78.

20 Pizarroso Quintero (2005).

21 Archivo General Militar de Ávila (AGMAV), C. 1870, 22, febrero de 1938. 
sometidos a un adiestramiento constante para paliar las deficiencias de las que adolecía su formación, hasta el punto de que unidades desplegadas en frentes estabilizados llegaban a ejercitarse diariamente ${ }^{22}$. Esta formación tenía dos dimensiones fundamentales: una práctica, relativa al manejo de armas y el aprendizaje de tácticas de combate; y otra teórica, no solo relacionada con la adquisición de conocimientos militares, sino también vinculada a la socialización de valores castrenses. Este último componente, denominado educación moral del soldado, tenía mucho que ver con la creación por parte del Ejército de sus propios instrumentos propagandísticos vinculados a la formación de las tropas — con el Servicio de Información y Policía Militar como principal organismo-, viéndose favorecido por el adiestramiento constante al que eran sometidos los soldados ${ }^{23}$. Por ejemplo, según una orden de instrucción dada a las nuevas unidades incorporadas a la 117 División de Infantería (DI) en agosto de 1937, se dedicaban al menos dos horas al día a la formación teórica, una a cómo hacer fuego con las armas disponibles y otra a «[...] la enseñanza de las obligaciones del soldado y su educación moral», si bien en el detalle concreto de los temas que abordar en esta segunda parte solo se hacía referencia a cuestiones de índole militar, como los valores castrenses ${ }^{24}$. El hecho de que la tropa dedicase el mismo tiempo a una cuestión capital, como el aprender a disparar eficientemente, que a su formación en valores castrenses denota que el Ejército rebelde no tenía como única meta ganar la guerra, sino también encuadrar a las nuevas generaciones de españoles a través de un sistema de adoctrinamiento directo. Aprender a manejar armas correctamente incidía directamente en la marcha de la contienda, pero no tenía influencia alguna en la posguerra. Sin embargo, esa educación moral, aunque contribuía a la disciplina de las unidades y su mejor desempeño en combate, tenía sus miras puestas en la conformación del nuevo Estado. Lo cual, de hecho, refuerza ese doble objetivo a corto y medio plazo de la movilización bélica, incluso en una fecha tan temprana como agosto de 1937.

Inicialmente, la referencia exclusiva a los valores militares en esta y otras directivas podría inducirnos a pensar que la única pretensión era que los soldados se empapasen de una serie de ideas de jerarquía militar propias de cualquier ejército y que, consecuentemente, no existía tal propósito ideológico. De hecho, en otra directiva, esta de junio de 1938, el jefe del Cuerpo de Ejército (CE) de Aragón recordaba a las unidades bajo su mando la necesidad

22 AGMAV, C. 1549, 101, enero de 1938.

23 Núńez de Prado y Clavell (1992): 329.

24 AGMAV, C. 1881, 1, agosto de 1937. 
de reforzar la instrucción mediante ejercicios prácticos y teóricos en los que se cimentase la creencia en la disciplina férrea y la obediencia ciega, «[...] primera virtud militar ${ }^{25}$. Sin embargo, directivas similares incidían de forma más específica en los contenidos de la educación moral del soldado, lo que ayuda a comprender mejor sus objetivos. En unas normas dadas a las brigadas de la 82 DI se detallaban los temas abordados por la «instrucción teórica y moral a las tropas», a saber: «Disciplina. Virtudes Militares. Carácter espiritual y humano del Movimiento. Derechos. Deberes y sanciones. Código de Justicia Mili$\operatorname{tar}{ }^{26}$. Nuevamente predominaba la formación en valores castrenses, pero esta estaba indisolublemente unida a la socialización de los principios ideológicos que inspiraban la sublevación. Así, los contenidos sugieren esa confluencia de valores militares e ideológicos, los cuales no eran excluyentes entre sí, sino partes de una misma cosmovisión. Si los militares codificaban una particular concepción del deber, la masculinidad o la patria, claramente ideologizadas, la socialización de estos valores no era sino la socialización de los marcos de referencia construidos por el nuevo Estado, objetivo al que contribuían tanto los sectores más políticos de la sublevación como los puramente castrenses.

El contenido de esas charlas temáticas impartidas en el frente evidenciaba que existía una marcada preocupación por que los soldados interiorizasen una serie de ideas fuerza fundamentales que constituían el armazón mínimo de la ideología del bando rebelde, no solo para generar entre este colectivo apoyos al futuro régimen, sino también, como planteaba una circular enviada en noviembre de 1936 a la columna Los Arcos, «[...] para que con su auxilio pueda él [el soldado] contrarrestar con eficacia las teorías disolventes que hasta él pudieran llegar ${ }^{27}$. En este sentido, los ideólogos de la propaganda tendieron siempre a ofrecer discursos adaptados a las expectativas de cada uno de los grupos que componían el heterogéneo campo insurgente. Así sucedió con el filtrado de la narrativa de la Cruzada para Falange y el Requeté, en el que se enfatizaron aspectos concretos para cada grupo de acuerdo con sus particulares cosmovisiones ${ }^{28}$. En el caso de la masa combatiente conscripta, que en líneas generales no tenía una militancia política activa, ese discurso se enfocó desde una óptica mucho más materialista, conectando con cuestiones

AGMAV, C. 1297, 74, junio de 1938.

AGMAV, C. 1335, 11, noviembre de 1937.

27 AGMAV, C. 1347, 17, noviembre de 1936. De hecho, para paliar las numerosas deserciones que sufrían determinadas unidades se ordenaba incrementar la frecuencia de estas charlas, de dos por semana a diariamente. Véase AGMAV, C. 1274, 5, enero de 1939.

28 Bannister (2015). 
pragmáticas que afectaban directamente a sus vidas y las de sus familias. Si bien, al mismo tiempo, la explicación de los beneficios que comportaba la condición de «veterano de la Cruzada» se articulaba a través de un discurso con constantes referencias a las ideas fuerza que conformaban los marcos de referencia construidos por el bando rebelde ${ }^{29}$. En última instancia, este proceso tendió, a nivel individual, a responder más a la gratitud por las prebendas recibidas que a un convencimiento pleno alejado de la recompensa material asociada.

Un conjunto de escritos pertenecientes a la 75 DI nos permite conocer de primera mano el contenido de estas charlas, denominadas "conferencias patrióticas», que conformaban la educación moral del soldado ${ }^{30}$. Concretamente, se trata de las transcripciones y resúmenes de algunas de las recibidas por unidades de esta división en febrero de 1939. A primera vista, dos son los elementos que destacan. En varias ocasiones se deja constancia explícita de que estas charlas se impartían durante las horas de instrucción teórica, lo que confirma que esa parte del entrenamiento abordaba también cuestiones ajenas a la práctica militar ${ }^{31}$. Además, todos los conferenciantes sin excepción eran militares de distinto rango, desde alférez hasta teniente ${ }^{32}$. El hecho de que las charlas las impartiesen figuras reputadas dentro de las unidades, o en todo caso otros combatientes y no civiles, aumentaba exponencialmente su capacidad de permeación, pues la información procedía de individuos respetados por los soldados rasos. No en vano, uno de los principales vínculos de camaradería construido en las unidades militares eran las relaciones paternofiliales establecidas entre soldados y oficiales, algo muy presente en el relato combatiente y que el Cuartel General del Generalísimo (CGG) ordenó cultivar explícitamente $^{33}$. Por ende, el carácter referencial de estos oficiales para la tropa permitía potenciar los efectos de su mensaje propagandístico. De hecho, en los primeros compases de la guerra se habían detectado debilidades en la propaganda que recibían las unidades por falta de personal formado para este

29 Ese discurso y su función en términos de amalgama identitaria en Rodrigo (2013): $15-17$.

30 Este tipo de charlas también se impartían en los campos de concentración, como parte de las tareas de reeducación de los prisioneros republicanos. Véase Rodrigo (2005): 134.

31 Leira-Castiñeira (2018: 308) cuestiona la sistematicidad de estas charlas.

32 Véase también Matthews (2014): 177.

33 Dos ejemplos en Martín Vigil (1977): 168, y Caballero (1976): 33-34. La orden del CGG en AGMAV, C. 2580, 122, mayo de 1938, p. 6. Los capellanes también fueron figuras relevantes en este sentido. Véase Matthews (2014). 
tipo de tareas, generalmente individuos no cualificados o directamente civiles, algo que se intentó resolver rápidamente nombrando «[...] oficiales que por sus cualidades y mayor cultura den frecuentes conferencias a la tropa para mantener el espíritu y la moral de la misma ${ }^{34}$. Un ejemplo sería el caso del ya mencionado Paz, que por su formación como maestro fue requerido para impartir una conferencia sobre «[...] los fines del glorioso movimiento y las causas que lo motivaron ${ }^{35}$.

Las charlas impartidas en la 75 DI combinaban contenidos netamente ideológicos, otros vinculados a los valores militares, y cuestiones relativas a la legislación social y asistencial que el nuevo Estado estaba implementado de cara a proteger a la población de los rigores de la guerra, especialmente a los combatientes y sus familias. Esta variedad de temas resulta especialmente interesante, pues la 75 DI era una unidad compuesta mayoritariamente por conscriptos encuadrados en batallones de infantería, y contaba únicamente con dos banderas falangistas procedentes de Galicia. Es decir, que nos encontramos ante un caso en el que se combina de forma evidente propaganda política y cultura castrense en el seno de una unidad tipo del Ejército sublevado. La documentación ofrece las transcripciones de trece conferencias concretas, resúmenes más o menos extensos de otras nueve, y un listado nominal de varias recibidas por uno de los batallones de la división, el $1 .^{\circ}$ de Montaña Sicilia n. ${ }^{\circ}$ 8. De las veintidós conferencias perfectamente identificables, y excluyendo las del batallón de montańa que luego detallaré, once tenían un contenido netamente ideológico, cinco se centraban en aspectos pragmáticos aunque utilizando un lenguaje claramente ideologizado - ciertamente todas estas charlas estaban siempre permeadas de este tipo de lenguajes-, dos combinaban ambos aspectos por igual, dos abordaban cuestiones de utilidad práctica para la vida de los soldados en el frente, y otras dos ahondaban en la relación entre los aspectos políticos y militares de la sublevación.

Las charlas cuyo enfoque era esencialmente ideológico giraban en torno a los temas habituales del discurso rebelde, como por ejemplo la relación de la Guerra Civil con momentos clave de la historia de España — los Reyes Católicos o la conquista de América - en los que la nación española había iniciado una etapa gloriosa empleando la guerra como proceso de purificación nacional ${ }^{36}$. Igualmente, charlas tituladas "Nacionalsindicalismo. Doctrina de temple hispánico», «Sobre la significación del glorioso movimiento nacional»

34 Véanse Núñez de Prado y Clavell (1992): 330, y AGMAV, C. 1590, 33, noviembre de 1938, p. 2.

35 Paz Fernández (1973): 7-8.

36 Esa conexión palingenésica en detalle en Gallego (2014): 785-842. 
o «Exposición y comentario de los puntos de FET y de las JONS» buscaban instruir a los combatientes en los principios elementales del ideario del Movimiento. Así, la última se centraba en diferenciar los sistemas políticos detrás de cada uno de los bandos en liza: el «viciado» liberalismo, cuyo enredado parlamentarismo democrático impedía una efectiva solución de los problemas del país; y el eficaz sistema totalitario (mencionando explícitamente a Italia y Alemania), que garantizaba la participación de todos a través de las organizaciones sindicales y en el que el Caudillo representaba la voluntad nacional. A continuación, detallaba la organización del nuevo Estado sobre la base de dos principios elementales: el respeto al individuo y la propiedad privada, y la garantía del orden social, es decir, de una libertad que no se tornase en «[...] libertinaje». El contenido presentaba una cosmovisión maniquea, sencilla de comprender e interiorizar por la tropa, construida sobre elementos fácilmente identificables por el español de a pie como la ineficiencia del sistema parlamentario o la necesidad de coartar unas libertades individuales que, entendidas de una forma amplia como en época republicana, suponían una amenaza al orden social imperante y a la propiedad privada. Es decir, que se buscaba socializar esas ideas elementales conectándolas con problemas y realidades tangibles, y no como meros constructos teóricos alejados de la cotidianidad de los combatientes.

Por otro lado, aquellas conferencias que tenían un enfoque más pragmático pretendían convencer a los soldados de los beneficios que conllevaba el advenimiento del franquismo, incentivándoles a seguir sacrificándose en los frentes y a mantenerse leales, o por lo menos aquiescentes, en la posguerra ${ }^{37}$. En una charla titulada "Principales reformas sociales empleadas ya por la España Nacional» se daba cuenta de los logros obtenidos por el nuevo régimen que afectaban directamente a los combatientes y sus familias: «I.- El auxilio a las familias de los combatientes. II.- El plato único. III.- La exención del pago de alquileres al obrero en paro forzoso. IV.- El salario familiar. V.- El patronato anti-tuberculoso. VI.- La obra de Auxilio Social». Elementos que, sobre un trasfondo ideológico poco marcado, definían la oferta que el franquismo presentaba a sus soldados, centrada en asegurar el sustento de las familias mientras los hombres combatían. Esta cuestión permite matizar esa idea del Ejército como un organismo que esencialmente utilizaba la represión, la coerción y el señalamiento de la disidencia como formas de control de sus integrantes $^{38}$. Además de eso, el propósito era que los soldados aceptasen voluntariamente la sumisión a la férrea cultura jerárquica castrense mediante

37 Hernández Burgos (2016b): 127-128.

38 Esta idea, fundamentalmente, en Leira-Castiñeira (2018). 
el otorgamiento de una serie de prebendas como contrapartida, las cuales en el contexto de un país devastado por la guerra pasaban más por la normalización de la vida social y económica, por el establecimiento de mecanismos de ayuda para afrontar la posguerra y por la creación de puestos de trabajo, que por lo puramente ideológico.

Otra de las conferencias, sin título, aludía a cuestiones similares. En primer lugar, explicaba el trabajo en materia asistencial que el Gobierno había ido realizando como forma de compensar el enorme sacrificio de los soldados. $\mathrm{Al}$ encontrarse luchando en el frente, estos no eran conscientes «[...] de lo que, allá lejos, en nuestra sana y laboriosa retaguardia, se labra para que, cuando victoriosos regresemos a nuestros hogares, hallemos estos encauzados hacia una era fecunda y próspera [...] que, todos vosotros, habéis soñado en las horas tensas y vibrantes en que poníais todo vuestro esfuerzo, vuestra sangre y vuestra vida en la defensa de los sacrosantos ideales de Dios, Patria y Justicia». En este breve fragmento actuaban los principales mecanismos empleados para maximizar el potencial de convencimiento de estas conferencias. Por una parte, la identificación del orador — un alférez en este caso- - con sus oyentes resultaba crucial, no solo porque los soldados lo veían como a otro miembro de la comunidad combatiente, sino porque admitía compartir sus mismos anhelos y preocupaciones. Por otra, la referencia explícita al combate, las heridas y la muerte de los compañeros buscaba subrayar que el trabajo realizado en retaguardia para recompensar el esfuerzo en el frente estaba a la altura de las expectativas de los soldados y su sacrificio. De hecho, los recelos hacia la falta de compromiso de la retaguardia eran un tema habitual en el relato combatiente, tal y como afirmaba el conscripto gallego Fernando Villalba al reproducir en sus memorias las estrofas de una canción popular entre los soldados que calificaba a los «retaguardistas» de «[...] enchufaditos [...] sentados en el café ${ }^{39}$. El encuadramiento forzoso de cientos de miles de individuos ofrecía una oportunidad única para monitorizar sus necesidades y generar unas políticas acordes a estas, algo que se intentaba aprovechar a través de formas de propaganda que abordasen aspectos fundamentalmente pragmáticos - aunque con un barnizado ideológico-y que explotasen los vínculos de la camaradería combatiente. Así, el control y la vigilancia no solo tenían una función coercitiva, sino que eran fundamentales para la construcción de los apoyos sociales a la dictadura.

En segundo lugar, la conferencia abordaba su objeto principal, la explicación del Fuero del Trabajo, aderezada de referencias a los pilares ideológicos del nuevo Estado, como el culto al líder carismático: «[...] humanas medidas

39 Villalba Diéguez (1956): 28. 
salidas de la privilegiada mente del Caudillo». Se detallaban los diversos capítulos del Fuero incidiendo en su componente de libertad individual, en comparación con los sistemas comunistas: en la España franquista no se produciría «[...] con un exceso que será perjudicial», dejando atrás aquellos años (republicanos) en los que se trabajaba para otros a cambio de un escaso jornal. Además, el Fuero prohibía el trabajo nocturno para mujeres y niños y que las mujeres casadas formasen parte del mercado laboral, lo cual "protegía» a las familias, sancionaba el modelo social de domesticidad femenina y, sobre todo, aseguraba el trabajo de los excombatientes, combinando así pragmatismo e ideología ${ }^{40}$. En esta misma línea, se atacaba la inestabilidad social de la República presentando el Fuero como el garante de los derechos de los trabajadores frente a los patronos, aunque conllevaba la pérdida de libertades individuales y políticas y la exigencia del «[...] máximo esfuerzo, la máxima producción». A lo largo de todo el texto, las promesas formuladas por el Fuero del Trabajo — vacaciones, subsidios, pensiones o seguros de accidente- se iban incardinando con un conjunto de expresiones ideologizadas que establecían una conexión rápida y sencilla entre que «[...] a cada familia le dará una parcela» y que esta, con su trabajo, "[...] eleve un canto a la Espańa inmortal que renace». El lenguaje no era en absoluto sutil, aunque huía de toda complejidad retórica para adecuarse a las posibilidades y expectativas de su audiencia, haciendo mucho más efectiva la transmisión del mensaje.

Las charlas también buscaban cultivar la idea de que los ámbitos militares y políticos de la sublevación estaban perfectamente sincronizados y representaban dos pilares de un mismo proyecto ${ }^{41}$. Las conferencias impartidas al 1. ${ }^{\text {er }}$ batallón de Montaña de Sicilia n. 8 mezclaban cuestiones ideológicas y pragmáticas — «Situación de nuestra Patria antes del Movimiento Nacional, y durante el mismo» o "Subsidio pro-combatiente»—, con otras que hacían referencia a valores militares — «Patriotismo, sacrificio y heroísmo» u «Honor militar»— o a la relación de estos con aspectos más políticos — «Unión compenetrada entre el Ejército y el pueblo, representado genuinamente en las milicias nacionales, para salvar la patria». En este sentido, lo militar se enmarcaba en un contexto netamente ideologizado, sin establecer diferenciación alguna entre una línea de adoctrinamiento castrense y otra política. Ambos elementos convivían sin mayores problemas y evidenciaban que la propaganda del Ejército se situaba en unas coordenadas definidas por el discurso político que unía a los diferentes componentes de la sublevación.

\footnotetext{
40 La competencia entre mujeres y excombatientes por el trabajo era un problema que ya habían padecido países como Italia tras la Gran Guerra. Véase Alcalde (2017): 79.

41 Rodrigo (2013): 29-30.
} 
Sin ir más lejos, una de las charlas, titulada «El Cuartel y la familia», desarrollaba la importancia de los valores militares para la construcción de la comunidad nacional, articulada a través de la familia. Se hacía hincapié en la disciplina, la jerarquía y la subordinación a la autoridad masculina como elementos indispensables para el resurgir nacional, vehiculado a través de un nuevo orden social con la familia tradicional en su centro. Por ende, mediante la imposición de una estructura jerárquica y ultramasculinizada en el ámbito familiar se reproducía, en todos y cada uno de los hogares en los que hubiera un combatiente, el modelo vertical que ordenaría a la sociedad. El combatiente vertía su experiencia de educación moral en sus espacios de influencia, en este caso en su familia, convirtiéndose en una correa de transmisión esencial de la cultura construida al calor del conflicto y, consecuentemente, en un agente de socialización ideológica mediante la puesta en práctica de los valores adquiridos durante su periodo de encuadramiento en las Fuerzas Armadas ${ }^{42}$. Un rol que, además, le reportaba contrapartidas materiales.

En definitiva, lo que el contenido de estas charlas deja claro es que la instrucción teórica del soldado incluía una formación en cuestiones ideológicas. No solo se centraba en inculcar valores castrenses, que dicho sea de paso estaban perfectamente insertos en un marco de referencia ideologizado, sino también en compartir contenidos netamente políticos, convirtiendo el encuadramiento castrense en una experiencia de ideologización. Además, la educación moral del soldado buscaba rentabilizar sus necesidades y temores, como la preocupación por la familia en retaguardia o el miedo a resultar herido y no poder posteriormente trabajar. Por ejemplo, el veterano Luis López Vázquez suplicaba la concesión de "[...] la Medalla de sufrimientos pensionada con la pensión que pueda corresponderme por las heridas recibidas en la Defensa de la Patria», ya que padecía de paraplejia, incapacidad de controlar sus esfínteres y úlceras por decúbito. Algo similar a lo que le sucedía al excombatiente y jornalero de profesión Gustavo Novo Ramilo, que no podía ejercer como tal al tener una impotencia funcional en el brazo derecho consecuencia de varias heridas sufridas en $1937^{43}$. Los soldados veían diariamente casos como los de Novo Ramilo o López Vázquez, cuya supervivencia y la de sus familias quedaban condicionadas a la obtención de una pensión estatal, lo cual

42 También en Vincent (2006). Esa función tenía además un componente muy importante de vigilancia y represión en las comunidades locales. Véase Hernández Burgos (2016b): 136.

43 Véase Archivo General Militar de Guadalajara, Fondos Regimiento Mérida n. ${ }^{\circ}$ 35, caja 2, documentos 12 y 37. Sobre los excombatientes discapacitados véase Wright (2016). 
generaba una ansiedad que les hacía especialmente receptivos a este tipo de propaganda ${ }^{44}$. El miedo a quedar lisiado, la corrupción que imperaba en retaguardia - con funcionarios que se quedaban con parte del subsidio destinado a las esposas de los combatientes, u oficiales del Ejército que malversaban el salario de los soldados_ $-{ }^{45}$, la represión o el simple desamparo de las familias eran argumentos de peso para aceptar la oferta de un Estado en construcción que, a cambio de la fidelidad del combatiente, no solo ofrecía protección, sino además unas jugosas contrapartidas económicas y asistenciales. Quizá por ello, afirmaciones como la que se incluía en una de las charlas patrióticas impartidas a la $75 \mathrm{DI}$, «[...] el Estado vela, y; ay del que quiera ir en contra de vosotros. El Estado no lo perdona», cobraban mayor relevancia, ofreciendo a los soldados una vía, mediante la adhesión al régimen, a través de la cual garantizar el bienestar de los suyos en retaguardia ${ }^{46}$.

\section{COLONIZAR EL OCIO Y EL TEDIO. PRENSA Y LECTURAS COMO VECTORES DE PROPAGANDA}

El otro gran instrumento de adoctrinamiento de los soldados fueron los libros y la prensa enviados al frente desde los primeros días de la guerra. Su importancia era capital, ya que permitían a la propaganda penetrar en los espacios de ocio y tedio, que constituyeron una parte muy significativa de la experiencia combatiente ${ }^{47}$. Ya en enero de 1937, el Cuerpo Facultativo de Archiveros Bibliotecarios estableció un servicio de lectura en hospitales y frentes, cuyo éxito animó a sus impulsores a intentar extenderlo a todos los frentes en los que combatía el Ejército rebelde mediante el envío de libros a las diferentes unidades ${ }^{48}$. Igualmente, en noviembre de 1938, el Ministerio del Interior decretó un envío masivo de libros a las tropas con la vista puesta en la inminente victoria y la necesidad de consolidar los apoyos sociales del nuevo Estado. Sin embargo, la iniciativa se topó con el problema de la falta de

44 Estas preocupaciones se reflejaban en las cartas que muchos españoles enviaban a Franco. Véase Cazorla Sánchez (2014). La idea de la mayor eficiencia de estas contrapartidas tangibles en Alcalde (2014): 212-213.

45 Dos casos en AGMAV, C. 1870, 22, febrero de 1938, y AGMAV, C. 2374, L. 145, 43, mayo de 1937.

46 Todas las referencias a las charlas impartidas a las unidades de la 75 DI provienen de AGMAV, C. 1816, 13, febrero de 1939 y sin fecha.

47 Leira-Castiñeira (2018): 310.

48 AGMAV, C. 1211, 54, enero de 1937. 
transportes militares, lo que comportó una reestructuración del servicio mediante la que se creó un almacén de libros en el Servicio Nacional de Propaganda para las unidades que los solicitasen ${ }^{49}$. La temática de estas publicaciones seguía una línea similar a la de las conferencias patrióticas, basculando entre lo ideológico y lo pragmático. Por ejemplo, en una lista de libros y folletos enviados en enero de 1939 a la 107 DI figuraban tanto títulos netamente ideológicos - La guerra española entre la moral y el derecho, Tres discursos de José Antonio o Poema de la Bestia y el Ángel_ como otros que presentaban un enfoque aparentemente más pragmático - Palabras del Caudillo, La Nueva España Agraria o Los combatientes y el Caudillo_, siendo más demandados los segundos ${ }^{50}$.

La preocupación por satisfacer las necesidades materiales de los soldados estaba muy presente en las normas de propaganda entregadas a las divisiones; normas que buscaron una implicación activa de los propios combatientes con el objetivo de refinar los instrumentos propagandísticos empleados por el Ejército. Una directiva de enero de 1939 señalaba que sería beneficioso recabar la opinión de las tropas sobre cómo se estaba enfocando la propaganda propia, cómo podrían mejorarse sus efectos y qué opinión les merecían sus contenidos, especialmente los relativos a las políticas asistenciales proyectadas por la dictadura. Esto motivó la puesta en marcha de un concurso para que los soldados elaborasen trabajos explicando la importancia de estas leyes, los mejores de los cuales serían gratificados con un premio sin determinar. Sin embargo, lo más relevante era el perfil de trabajos que se buscaba: «[...] los que indiquen que con mayor claridad que los restantes, han percibido sus autores cuál es la intención de la Ley "Auxilio social" ${ }^{51}$. Es decir, que no se pretendía que los combatientes supiesen articular un discurso complejo acerca de la naturaleza de esta legislación, sino más bien que entendiesen lo que esta les ofrecía y las necesidades familiares y personales que satisfacía. La voluntad de integrar al mayor número de españoles posible era uno de los leitmotiv esenciales, por lo que una discriminación por criterios culturales resultaba tremendamente inefectiva.

Las propias consignas de propaganda subrayaban la necesidad de combinar un enfoque pragmático con otro más ideologizado. Un escrito de la 16 DI de enero de 1938 centraba el interés propagandístico en dos temas

49 AGMAV, C. 1224, 14, noviembre de 1938. No obstante, este servicio de demanda de libros parecía estar disponible desde hacía un tiempo, según AGMAV, C. 1897, 19, marzo de 1938.

50 AGMAV, C. 1865, 5, enero de 1939, p. 27.

51 AGMAV, C. 1865,5 , enero de 1939, p. 7. 
muy concretos: los avances cosechados en Teruel y los crímenes cometidos en zona republicana, especialmente las profanaciones de lugares sagrados católicos $^{52}$. Esto último buscaba conectar con el catolicismo de muchos combatientes, que sin necesidad de ser fervientes creyentes entendían la violencia antirreligiosa como algo absolutamente intolerable. Además, no hay que olvidar el sobredimensionamiento de este tipo de actos con fines propagandísticos, algo que se empezó a cultivar ya desde agosto de 1936 cuando se ordenó a los jefes de las columnas Yagüe, Tella, Castejón y Varela fotografiar los desmanes cometidos por las fuerzas republicanas en los pueblos que fuesen ocupando, "con el fin de poder editar un folleto en el que conste de una manera gráfica las barbaridades que las turbas rojas cometen [...]. Este folleto se piensa enviar a todo el mundo para que se sepa lo salvaje que es el enemigo que se combate ${ }^{53}$.

Por su parte, la referencia a los avances militares ejemplifica nuevamente cómo los elementos ideológicos y los puramente castrenses perseguían un mismo objetivo, algo en lo que los partes de guerra fueron un instrumento más de la maquinaria propagandística rebelde. Al tiempo que alimentaban los lazos de camaradería e identificación construidos en torno a la pertenencia al colectivo del Ejército sublevado, reforzaban la moral exagerando la importancia de las victorias y minimizando las derrotas, que siempre se presentaban bajo fórmulas matizadas como «evacuación» o "repliegue» y de las que, si era posible, se culpaba a individuos concretos, como sucedió con el coronel Rey d'Harcourt durante la batalla de Teruel $^{54}$. Así, en enero de 1939 un telegrama enviado por el comandante del CE Castilla a su homólogo de la 15 DI subrayaba la necesidad de que los soldados conociesen el parte oficial de guerra y que fuese «[...] comentado su contenido haciendo [...] un resumen de nuestros triunfos y de las pérdidas del enemigo y consideraciones acerca del estado de las filas y la retaguardia enemiga y su comparación con las nuestras $»^{55}$. El parte funcionaba como una charla patriótica más, relacionando lo militar con lo que sucedía en las retaguardias, socializando el discurso rebelde a través de varios canales simultáneos y potenciando su incidencia.

52 AGMAV, C. 1602, 30, enero de 1938.

53 Archivo General de Palacio, Fondo Jefatura del Estado, Casa Civil de S. E. el Jefe del Estado, Caja 20, Legajo 149, agosto de 1936. Rodrigo (2013): 31-44. Leira-Castiñeira (2018): 134 y 309.

54 Núñez de Prado y Clavell (1989): 211-222. Esa idea de camaradería basada en la pertenencia al Ejército en Kühne (2017): 147-148. El caso de Teruel en Alegre Lorenz (2018a): 280-281.

55 AGMAV, C. 1594, 10, enero de 1939. 
Otras dos directivas de septiembre de 1938 y enero de 1939 abordaban sendas formas alternativas de propaganda en el frente, como el lanzamiento de octavillas y el empleo de altavoces en primera línea. Las primeras se centraban en contrarrestar la propaganda republicana canalizada a través de periódicos que informaban de supuestos desórdenes en la retaguardia rebelde, lo que incidía en la principal preocupación de los soldados, esto es, el bienestar de sus familias. Sin ir más lejos, la directiva ordenaba subrayar a los combatientes que «[...] nada falta a vuestras familias y que el trabajo continúa normalmente produciendo lo preciso", proyectando a su vez esa imagen de caos sobre el lado republicano. Es decir, que la lucha propagandística se trató fundamentalmente de un combate por lo material ${ }^{56}$, a través de lo cual se iba introduciendo lo ideológico. En este sentido, las octavillas no olvidaban esa dimensión, que entre los temas sugeridos tenían la demonización del rojo o la construcción de una alteridad en clave de clase ${ }^{57}$.

Por su parte, la directiva de enero de 1939 insistía en que la propaganda debía centrarse en explicar los avances del Ejército rebelde, los beneficios que comportaban el Fuero del Trabajo y la legislación asistencial creada por el nuevo Estado, y una relectura de la historia en clave palingenésica, abarcando así las dimensiones pragmática e ideológica. Sin embargo, también apuntaba una cuestión esencial del modo en que debía elaborarse dicha propaganda. Uno de los temas que tratar era la «unidad de destino en lo universal». «Unidad geográfica, histórica y religiosa», recomendándose «vulgarizar estos conceptos de manera muy clara». El objetivo no era entender esta cuestión en toda su complejidad, sino transformarla en una noción muy rudimentaria fácilmente comprensible por los soldados. Si la vía más eficaz para penetrar en los soldados era abordar sus problemas materiales, a nivel ideológico era suficiente con que interiorizasen unas nociones muy básicas. Además, se trataba de llegar a cuantos más individuos mejor, lo que pasaba por la adaptación del discurso a los lenguajes y niveles educativo-culturales del conjunto de la masa combatiente $^{58}$. De hecho, la propia directiva apuntaba claramente en esta dirección al exponer las líneas maestras del diseño de la propaganda, extraídas del Mein Kampf: «Toda acción de propaganda tiene que ser necesariamente popular, y adaptar su nivel intelectual a la capacidad receptiva del más limitado de los individuos a los cuales está destinada. De ahí que su grado

\footnotetext{
Seidman y Ferrandis Garrayo (1997): 46.

AGMAV, C. 1201, 14, septiembre de 1938.

58 Por ejemplo, en los cursos de sargentos provisionales, con varias vías de acceso en función del nivel de estudios de los candidatos. Véase AGMAV, C. 1549, 58, agosto de 1937.
} 
puramente intelectual deberá regularse tanto más hacia abajo, cuando más grande sea el conjunto de la masa humana que ha de abarcarse, ${ }^{59}$.

Este mismo enfoque se aplicó en retaguardia a diferentes iniciativas impulsadas por las jefaturas provinciales de FET y de las JONS para la elaboración de folletos propagandísticos sobre el ideario falangista y los beneficios de la legislación creada por la dictadura. En una carta enviada en diciembre de 1938, Jorge Claramunt, jefe provincial en Vizcaya, solicitaba autorización para uno de estos pasquines: «Se trata de hacer llegar a las masas de nuestra provincia, de un modo simple y directo, con los postulados renovadores y las realidades de lo ya legislado, el sentido que informa nuestra revolución nacional $»^{60}$. Enfoque «simple y directo» que compartía una iniciativa similar puesta en marcha en mayo de 1938 por la jefatura de Santa Cruz de Tenerife. La idea era editar un pequeño libreto con textos doctrinales de los principales dirigentes del Movimiento, como José Antonio Primo de Rivera, Onésimo Redondo o el propio Franco, al que «[...] se le quiere dar un carácter popular, recogiendo en él solamente lo que se halle al alcance de las gentes», incrementando así su capacidad de alcance ${ }^{61}$.

Por tanto, no se pretendía, ni de hecho se podía, convertir a la población en individuos conscientes de lo que eran el fascismo o la contrarrevolución, sino que el objetivo era que adaptasen dicha ideología a su cotidianidad mediante la satisfacción de sus necesidades materiales. Esto permite plantear la idea del control social desde otra perspectiva. La socialización puramente ideológica y la represión no bastaban para sostener la dictadura, siendo imprescindible atender a las demandas de los españoles corrientes mediante un paquete de medidas que les sedujese y les atrajese: la oferta del nuevo Estado. Esa incapacidad de imponer su voluntad de forma aproblemática permite cuestionar la noción de la naturaleza todopoderosa del Estado, teniendo que «negociar» las condiciones de incorporación de grandes capas sociales a su proyecto. De ahí que se hiciese tanto hincapié en ofrecer más que en convencer, y en ofrecer de un modo simple, directo y perfectamente comprensible para todos.

Volviendo al frente, la prensa también colaboró en atraer a los combatientes a la dictadura. De hecho, se trataba de un mecanismo propagandístico en sí mismo, con unos contenidos controlados mediante la aplicación de una estrecha censura ${ }^{62}$. Así, se consiguieron colonizar esos espacios de ocio

59 AGMAV, C. 1865, 5, enero de 1939, pp. 2-3. La cursiva en el original

60 Archivo General de la Administración (AGA), C. 21/00041, 59, documento 101, 3 de diciembre de 1938.

61 AGA, C. 21/00041, 59, documento 121, 27 de mayo de 1938.

62 Sobre la prensa como instrumento de propaganda véanse González Calleja y Limón Nevado (1988) y Langa Nuño (2001). 
y tedio antes mencionados, donde otras formas de propaganda tenían mayores dificultades para penetrar, vinculando la socialización del discurso rebelde a las cuestiones que interesaban a los combatientes, incluso las más triviales como el deporte. El Ejército procuró que la prensa llegase en buen número y sin demasiado retraso a las unidades desplegadas tanto en el frente como en segunda línea, lo que demuestra la relevancia concedida a este vehículo de propaganda. Ya en septiembre de 1936, un representante de $A B C$ Sevilla informaba de que los paquetes destinados a las columnas estaban siendo vendidos en las calles de la capital hispalense, y los dirigentes rebeldes ordenaban que el problema fuese inmediatamente solucionado ${ }^{63}$. En diciembre de ese mismo año, el Estado Mayor del CE de Madrid se quejaba también de que la prensa propia no era distribuida a las unidades bajo su mando, a las que sí llegaban diarios lanzados por el enemigo que podían "[...] ejercer influencia en el ánimo de nuestros soldados». Consecuentemente, al tiempo que se prohibía la lectura de prensa enemiga se ordenaba la creación de un servicio de coches ligeros para asegurar la distribución de la propia: «[...] la Prensa debe llegar hasta el último punto donde se encuentre un oficial con su sección [...] dada la importancia que tiene [...] [su] divulgación ${ }^{64}$.

Pese a estos problemas iniciales, los diarios comenzaron a llegar regularmente a primera línea desde, al menos, marzo de 1937. Esa aparente buena distribución de la prensa se desprende de una serie de hojas de comprobación cumplimentadas en dicho mes por combatientes pertenecientes al CE de Madrid. En ninguna de las doce hojas conservadas se indicaba que el tiempo entre la recepción del periódico y la fecha del mismo excediese los dos días, aunque esta demora era la más habitual. Igualmente, se observa que la mayoría de la prensa era de corte generalista, pues solo en dos casos se mencionan diarios de temática específica, uno de los cuales era La Ametralladora ${ }^{65}$. No obstante, si nos atenemos a los testimonios de los propios combatientes, la eficiencia del servicio de distribución de prensa variaba en función de cada unidad. Mientras que el teniente médico José Aznares afirmaba que en su división «Siempre hemos estado, y estamos, muy bien servidos en Prensa», el alférez provisional José Luis Martín Vigil apuntaba que, durante la estancia de su unidad en un frente estabilizado, no tenían «[...] nada que leer si no es

\footnotetext{
63 AGMAV, C. 2374, L. 146, 1, septiembre de 1938.

64 AGMAV, C. 1396, 5, diciembre de 1936. También en Matthews (2012): 73. Otra petición de distribución de prensa en AGMAV, C. 2328, L. 54, 33, diciembre de 1936.

65 AGMAV, C. 1901, 5, marzo de 1937. Matthews (2012): 74.
} 
algún número viejo de "La Ametralladora” ${ }^{66}$. En cualquier caso, la escasez de la muestra analizada no permite establecer conclusiones extrapolables al conjunto del ejército sublevado acerca del funcionamiento general del servicio $^{67}$. Además, es posible que las particulares condiciones de los sectores en que estaban desplegados los soldados que respondieron al cuestionario — cada hoja procedía de una unidad diferente- explicase la fluidez del servicio.

De hecho, en fechas posteriores siguieron presentándose quejas por el retraso en la distribución de periódicos. En julio de 1937 la DNPP informaba al CGG de que soldados de varios frentes afirmaban no recibir ejemplares de La Ametralladora, ante lo cual el CGG ordenó a los mandos divisionarios asegurarse de que los diarios llegasen a sus hombres ${ }^{68}$. Estos problemas motivaron la introducción, en octubre de 1938, de una serie de formularios de control a cumplimentar periódicamente por las secciones segundas de los estados mayores de las divisiones. Además, se animó a las unidades a proponer sugerencias para «[...] lograr que el periódico sea leído en fecha lo más próxima a su publicación». Así, se ordenaba que las unidades adaptasen su estructura de distribución en función de si estaban en un frente estabilizado o activo y de cuánto terreno tenían bajo su control, con el fin de atender la «[...] diaria obligación [de] hacerla llegar hasta las diferentes posiciones e incluso avanzadillas, [...] para que ninguna de ellas, por reducida o alejada que esté, deje de recibir diariamente la Prensa que se le envíe» ${ }^{69}$.

Todas estas medidas evidencian el papel primordial que tenía la prensa como instrumento de propaganda con una evidente función ideológica. Esto redunda en la idea del encuadramiento en el Ejército como un mecanismo de socialización ideológica por diversos canales, haciendo así imposible disociar las metas políticas y militares de la sublevación. Mantener informados a los combatientes permitía contrarrestar la propaganda republicana - mitigando así la disensión y las deserciones - y, al mismo tiempo, presentarles la oferta que el régimen había diseńado para ellos. Por su parte, los avances militares, arrolladores a partir de marzo de 1938, eran aprovechados para vender la idea de la victoria y atraer a los combatientes hacia el nuevo Estado, no tanto por

66 Akela (1977): 131, y Martín Vigil (1977): 128. En la línea de Martín Vigil véase Centro Documental de la Memoria Histórica, Carpeta F814, "Declaración del evadido del campo rebelde (Juan Padrón Hernández)», folio 40.

67 En este sentido, la existencia, a la altura de abril de 1938, de unos cien periódicos editados al mismo tiempo en la zona rebelde contribuía a diversificar los esfuerzos. Véase AGA, C. 21/00041, 59, documento 12, abril de 1938.

68 AGMAV, C. 1220, 36, julio de 1937.

69 AGMAV, C. 1622, 2, octubre de 1938. 
convencimiento, sino por la constatación de que el conflicto estaba ya casi decidido y que la disidencia solo podía traer represión, exilio, cárcel o muerte. Por ello, se trabajó para que el contenido de los diarios fuese leído por todos los soldados, por ejemplo mediante «[...] lecturas de prensa en colectividad» para «[...] aquellos individuos que no sepan leer». El esfuerzo invertido fue considerable, especialmente si tenemos en cuenta que un modelo de distribución tipo asignaba 8100 periódicos para una división de unos 10500 efectivos $^{70}$.

La puesta en marcha de esta tarea propagandística necesitaba de un estricto control de los contenidos publicados, lo que motivó la erección de una importante estructura de censura de prensa ${ }^{71}$. Inicialmente, la voluntad de controlar la información se orientó más a evitar que se filtrasen datos sensibles de índole militar ${ }^{72}$, pero la progresiva construcción de estructuras estatales con una marcada orientación política y la convergencia hacia una guerra total requerían una mayor fiscalización de la información, algo que se fue implementando progresivamente. En agosto de 1937, el CGG envió una circular a los directores de periódicos y emisoras de radio, jefes de la censura y subdelegados de la DNPP en la que les instruía acerca de qué tipo de informaciones había que transmitir, cómo presentarlas, y cómo debían funcionar los servicios de información en la zona rebelde, siempre sobre el trasfondo de la función que la prensa cumplía en el esfuerzo bélico. Según se indicaba, la directiva había sido cuidadosamente confeccionada tras tres meses de estudio de la prensa y de cómo esta abordaba los acontecimientos en materia de política exterior e interior, lo que subrayaba la voluntad de maximizar su carácter propagandístico. La circular exigía que las noticias de política nacional se ajustasen al espíritu de los veintiséis puntos del programa de Falange, redundando por tanto en su función ideológica y no simplemente informativa. Además, debían cultivar la imagen de Franco como líder carismático, eliminando de sus páginas toda referencia a cualquier elemento o persona que cuestionase el poder único del Caudillo.

Lo que esta circular planteaba no eran unas simples directrices destinadas a definir los ámbitos de la censura informativa, sino que desarrollaba las líneas maestras de la propaganda rebelde a través de la prensa. Los diarios debían subordinarse completamente al esfuerzo de guerra, ejerciendo como instrumento de codificación y socialización del discurso ideológico de la

70 Id. No obstante, algunos combatientes rechazaban el contenido publicado por la prensa, calificándolo de «desinformación». Véase Leira-Castiñeira (2018): 300.

71 Sobre la censura de prensa véase Núnéz de Prado y Clavell (1992): 252-258.

72 AGMAV, C. 2319, L. 38, 50, febrero de 1937. 
nueva España, vehiculado mayoritariamente a través de la promoción de leyes y medidas concretas ${ }^{73}$. La sumisión, favorecida por la promulgación de la Ley de Prensa de abril de 1938, debía ser absoluta: «La responsabilidad del futuro no es ni de la prensa, ni de los que en ella puedan escribir, sino que es íntegra del Caudillo que rije [sic] los destinos de Espańa, y por consiguiente, suya totalmente es la autoridad». No obstante, los periódicos también debían esforzarse por ofrecer noticias atractivas, acordes a las normas dadas por el CGG, pero sin reproducirlas textualmente, ya que eso generaría un producto aburrido que alejaría a los lectores, como apuntaba el cronista de guerra Manuel Sánchez del Arco al calificar la prensa censurada de «[...] opaca y pobre», lo que hacía que soldados y público arrojasen "[...] los periódicos con desdén, y nuestros buenos propósitos fracasan ${ }^{74}$. Por ello, la circular señalaba que «[...] lo más importante es salvar la monotonía», adoptando como referencia diarios internacionales modernos como Daily Express o Paris Soir. Igualmente, el estilo debía ser directo y efectista, buscando artículos cortos, «[...] más difíciles de escribir, pero más fáciles de leer». Emplear lenguajes cercanos y en cierto modo coloquiales, alejados de la abstrusa retórica oficial, conectaba mucho mejor con un público al que había que simplificarle los contenidos mediante piezas breves e interesantes que, además, aludiesen a los elementos centrales del discurso que se quería socializar. Precisamente, esta precisión en las medidas que adoptar evidenciaba los considerables esfuerzos que pusieron los dirigentes sublevados en convertir la prensa en uno de los vehículos predilectos a través de los cuales construir la nueva España, no solo en sus páginas sino, esencialmente, en la mente y la vida cotidiana de sus lectores ${ }^{75}$.

\section{CONCLUSIÓN}

Los excombatientes fueron uno de los cimientos esenciales sobre los que se erigió el régimen franquista. Tras la guerra, la Delegación Nacional de Excombatientes (DNE) canalizó, mediante su condición de representante de los veteranos de guerra, todo el potencial legitimador y simbólico

73 Por ejemplo, un acuerdo del Comité Sindical del Papel y Cartón recomendaba, debido a la escasez de papel, denegar las autorizaciones a nuevas publicaciones si estas no contribuían al «[...] encauzamiento de la opinión pública». Véase AGA, C. 21/00041, 59, documento 12, abril de 1938.

74 AGMAV, C. 2539, L. 323, 22, diciembre de 1938

75 La circular en AGMAV, C. 2538, L. 322, 28, agosto de 1937. 
de este colectivo, poniéndolo al servicio de la dictadura. Sin embargo, el encuadramiento de los veteranos a través de la DNE solo nos habla de una parte minoritaria del conjunto de los excombatientes, la más comprometida ideológicamente. La otra, mayoritaria, se correspondía mucho mejor con la propia imagen de la movilización rebelde ${ }^{76}$. Es decir, la de un contingente heterogéneo en lo sociopolítico y que mostró diversas actitudes ante su conscripción, que aun no siendo de oposición no significaban en absoluto la adhesión a los principios de la sublevación ${ }^{77}$. Y es sobre esta parte mayoritaria sobre la que se ha de situar el foco. De este modo, la imposibilidad de penetrar por la vía de lo ideológico en una parte importante de la masa combatiente, sumada a la necesidad de construir un espacio como mínimo aquiescente para sostener la dictadura, condujeron al ofrecimiento de contrapartidas tangibles que abordasen los problemas reales de los soldados —familia, trabajo, asistencia médica- ${ }^{78}$. Esto no generó un apoyo activo entre buena parte de los veteranos de guerra, pero sí al menos una tolerancia instrumental hacia el franquismo que permitía la supervivencia de ambos.

En cualquier caso, la oferta planteada por el nuevo Estado a sus combatientes apunta hacia otra cuestión crucial: la doble tarea del Ejército rebelde, cuyo objetivo no era únicamente ganar la guerra, sino también ganar las mentes de los soldados mediante la propaganda ${ }^{79}$. Sin victoria militar no se podía construir el nuevo Estado, pero tampoco era posible poner en marcha un proyecto como el diseñado por los rebeldes sin incorporar a una gran mayoría de españoles. Esto evidencia el papel adoctrinador jugado por el Ejército desde el momento en que constató las posibilidades que le ofrecía - y las exigencias que comportaba- el marco propiciatorio generado por el fallido golpe de Estado y la progresiva articulación de una guerra total, no solo en términos de depuración interna, sino también de creación de un proyecto erigido sobre amplios apoyos sociales ${ }^{80}$. Es decir, que el Ejército se puso ente-

76 Alcalde (2014): 349-351.

77 Leira-Castińeira y Domínguez-Almansa (2018).

78 Hernández Burgos (2016b): 131.

79 Esto se evidencia en la importancia que se le concedía a la socialización ideológica en el propio adiestramiento de los soldados, a pesar de durar como máximo unos insuficientes treinta días. Véase AGMAV, 1550, 25, mayo de 1938. No en vano, la propaganda, aun controlada por los militares en última instancia, debía siempre responder a las directrices dadas por el Servicio Nacional de Propagnda «en cuanto afecta a su carácter político-social». Véase AGMAV, C. 1568, 13, septiembre de 1938.

80 Esa idea de la guerra como escenario propiciatorio en Rodrigo (2009): 18-19. 
ramente al servicio del incipiente régimen franquista, también en la construcción de los cimientos que lo sustentaron ${ }^{81}$.

La combinación de los dos elementos seńalados, esto es, el papel adoctrinador del Ejército y los límites que la heterogeneidad sociopolítica del contingente movilizado al calor de la conscripción impuso sobre el proceso de socialización ideológica, sugieren la necesidad de repensar el modo en que concebimos e interpretamos historiográficamente esa ideologización, tanto referida a los combatientes como al conjunto de la sociedad espańola. La necesidad del nuevo Estado de negociar la incorporación de los combatientes a su proyecto se vio replicada en las relaciones que el régimen estableció con los españoles corrientes durante la posguerra, tal y como ha señalado la historiografía dedicada a los apoyos sociales al franquismo ${ }^{82}$. En este sentido, fue la oferta material, y no la ideológica, la que ejerció como vector de incorporación principal al proyecto franquista, lo cual no implica que no existiese vínculo alguno con la dictadura en términos ideológicos, de cierta lealtad si se quiere. La satisfacción de necesidades concretas que entroncaban directamente con las realidades cotidianas de los españoles permitió construir esa relación, a través de un intercambio consciente de contrapartidas. Por ende, el proceso de encuadramiento y socialización ideológica de los combatientes, y al mismo tiempo del conjunto de la sociedad, ha de entenderse de un modo más amplio, menos vinculado a una participación activa en las iniciativas del régimen y más como la adaptación del discurso franquista a las realidades concretas de los individuos, siempre sobre la base de los potenciales beneficios que comportase una actitud por lo menos aquiescente.

Además, la comprensión del proceso constructivo del franquismo en estos términos permite matizar la narrativa historiográfica del fracaso de las políticas del régimen, al menos en lo que respecta a la utilización de sus límites como un termómetro para medir los apoyos de los que disfrutó la dictadura. La sugerida ampliación de la perspectiva, mediante la incorporación de variables como la cotidianidad, la contingencia o el cálculo de beneficios, construye una interpretación mucho más flexible de dichos apoyos, que huye de marcos dicotómicos y maximalismos y apuesta por entender la dictadura, y sobre todo a los individuos de a pie, en sus propios términos y contexto ${ }^{83}$. Porque, no olvidemos, el franquismo fue el único fascismo que salió vencedor

\footnotetext{
81 Incluso empleando la propia institución como recompensa, como sugiere la prevalencia de familiares directos de heridos o mutilados de guerra en la admisión a cursos de oficial y suboficial. Véase AGMAV, C. 1551, 21, diciembre de 1938, pp. 1 y 3.

82 Por ejemplo, Cabana (2011).

83 Rodríguez Barreira (2012).
} 
de su propia guerra. Esto convierte la habitual comparación directa con los fascismos alemán e italiano, derivada del modo en que se aplica el concepto de fascismo para el caso español ${ }^{84}$, en un ejercicio en cierto modo ventajista, dado que España ya no tenía ante sí un permanente horizonte bélico, como sí tuvieron hasta el final Alemania e Italia ${ }^{85}$. La victoria bélica redefinió por completo las necesidades y expectativas de movilización de un régimen que, a pesar de no alcanzar sus objetivos de encuadramiento social, no vio tambalear sus cimientos por ello ${ }^{86}$. No en vano, ya se había encargado de presentar una oferta lo suficientemente seductora como para asegurarse el apoyo, o por lo menos la aquiescencia, de una parte importante de la población.

\section{Bibliografía}

Akela [Aznares García, J.] (1977). Diario de operaciones de un teniente médico. Madrid: Biblioteca CIM.

Alcalde, Á. (2013). Los excombatientes en el mundo rural de la posguerra. Del mito del campesino soldado a la realidad social de la España franquista. En Ó. Rodríguez Barreira (coord.). El franquismo desde los márgenes: campesinos, mujeres, delatores, menores.... (pp. 113-129). Almería: Universidad de Almería.

- (2014). Los excombatientes franquistas. La cultura de guerra del fascismo español y la Delegación Nacional de Excombatientes (1936-1965). Zaragoza: Prensas de la Universidad de Zaragoza.

(2017). War Veterans and Fascism in Interwar Europe. Cambridge: Cambridge University Press. Disponible en: https://doi.org/10.1017/9781108182423.

Alegre Lorenz, D. (2018a). La batalla de Teruel. Guerra total en España. Madrid: La Esfera de los Libros.

(2018b). The New Fascist Man in 1930s Spain. En J. Dagnino, M. Feldman, y P. Stocker (eds.). The "New Man" in Radical Right Ideology and Practice, 1919-45 (pp. 215-229). London: Bloomsbury.

84 Alonso Ibarra (2017).

85 La sugerencia de Vincent (2006) de que la imposición de una masculinidad paternalista (carlista) durante la posguerra comportaba la derrota del ideal masculino fascista adolece de este mismo problema, al entender el énfasis en lo familiar y el hogar como un factor de desmovilización, y por ende contrario a lo que teóricamente representaría el fascismo, sin considerar el contexto construido en España después de abril de 1939: el de un fascismo que había sido capaz de trascender su propio horizonte bélico. Una crítica a esta idea de Vincent en Alegre Lorenz (2018b): 224. La configuración del discurso bélico y revolucionario por parte de Falange en posguerra en Gallego (2014): 729-733.

86 Esa insatisfacción de expectativas en Lanero (2010) o Rodríguez Barreira (2014). 
Alonso Ibarra, M. (2017). Los límites del fascismo en España. Un recorrido crítico por conceptos, interpretaciones y debates de la historiografía reciente sobre el franquismo. Stvdia Historica. Historia Contemporánea, 35, 135-170.

Bannister, C. (2015). Crusaders and Commisars: A Comparative Study of the Motivation of Volunteers in the Popular and National Armies in the Spanish Civil War, 1936-1939 [tesis doctoral inédita]. European University Institute.

Caballero, P. J. (1976). Diario de campaña (de un capellán legionario). Madrid, Doncel.

Cabana, A. (2011). De imposible consenso. Actitudes de consentimiento hacia el franquismo en el mundo rural (1940-1960). Historia Social, 71, 89-106.

Cazorla Sánchez, A. (2014). Cartas a Franco de los españoles de a pie (1936-1945). Barcelona: RBA.

Cenarro, Á. (2005). La sonrisa de Falange. Auxilio social en la guerra civil y en la posguerra. Barcelona: Crítica.

Cobo, F., Del Arco, M. Á., y Ortega, T. M. (2011). The Stability and Consolidation of the Francoist Regime. The case of Eastern Andalusia, 1936-1950. Contemporary European History, 20 (1), 37-59. Disponible en: https://doi.org/10.1017/S0960777310000366.

Corral, P. (2006). Desertores. La Guerra Civil que nadie quiere contar. Barcelona: Debate.

Del Arco, M. Á. (2007a). Hambre de siglos. Mundo rural y apoyos sociales del primer franquismo en Andalucía Oriental (1936-1951). Granada: Comares.

(2007b). «Hombres nuevos». El personal político del primer franquismo en el mundo rural del sureste español (1936-1951). Ayer, 65, 237-267.

Ferris, K. (2012). Everyday Life in Fascist Venice, 1929-1940. Basingstoke: Palgrave-Macmillan. Disponible en: https://doi.org/10.1057/9781137265081.

Gallego, F. (2014). El Evangelio fascista. La formación de la cultura politica del franquismo (1930-1950). Barcelona: Crítica.

Gellately, R. (2001). Backing Hitler. Consent and Coercion in Nazi Germany. Oxford: Oxford University Press. Disponible en: https://doi.org/10.1093/acprof:oso/ 9780198205609.001.0001.

González Calleja, E. (2012). La prensa carlista y falangista durante la Segunda República y la Guerra Civil (1931-1937). El Argonauta Español, 9. Disponible en: https://doi. org/10.4000/argonauta.819.

— - y Limón Nevado, F. (1988). La Hispanidad como instrumento de combate. Raza e imperio en la Prensa franquista durante la Guerra Civil española. Madrid: Consejo Superior de Investigaciones Científicas.

Hernández Burgos, C. (2011). Granada azul. La construcción de la "Cultura de la Victoria» en el primer franquismo. Granada: Comares.

- (2016a). Bringing back Culture: Combatant and Civilian Attitudes during the Spanish Civil War, 1936-1939. History. The Journal of the Historical Association, 101 (346), 448-463. Disponible en: https://doi.org/10.1111/1468-229X.12238.

(2016b). De la cultura de guerra a la cultura de la victoria: los vencedores y la construcción de la dictadura franquista (1936-1951). Pasado y Memoria. Revista de Historia Contemporánea, 15, 123-148. Disponible en: https://doi.org/10.14198/ PASADO2016.15.05. 
Jensen, G. (2014). Cultura militar española. Modernistas, tradicionalistas y liberales. Madrid: Biblioteca Nueva.

Kühne, T. (2017). The Rise and Fall of Comradeship. Hitler's Soldiers, Male Bonding and Mass Violence in the Twentieth Century. Cambridge: Cambridge University Press. Disponible en: https://doi.org/10.1017/9781107110106.

Laín Entralgo, P. (2011) [1936-1938]. Sermón de la Tarea Nueva. Mensaje a los intelectuales católicos. En Jerarquía. La revista negra de la Falange (1936-1938) (pp. 75-90). Madrid: Ediciones Barbarroja.

Lanero, D. (2010). ¿La salud es lo que importa? La O. S. 18 de Julio y la asistencia médica en Galicia (1940-1956). Historia Social, 68, 47-67.

Langa Nuńo, C. (2001). Educación y propaganda en la Sevilla de la Guerra Civil. Una aproximación a través de la prensa. Sevilla: Ayuntamiento de Sevilla.

Leira-Castińeira, F. J. (2018). La socialización de los soldados del ejército sublevado (19361945). Su papel en la consolidación del Régimen franquista [tesis doctoral inédita]. Universidade de Santiago de Compostela.

— , y Domínguez-Almansa, A. (2018). Reclutados para ganar. Movilización y respuesta de «los soldados de Franco». Ayer, 111, 79-107.

Llordés, J. (1968). Al dejar el fusil. Memorias de un soldado raso en la guerra de España. Barcelona: Ariel.

Matthews, J. (2012). Reluctant Warriors. Republican Popular Army and Nationalist Army Conscripts in the Spanish Civil War, 1936-1939. Oxford: Oxford University Press. Disponible en: https://doi.org/10.1093/acprof:oso/9780199655748.001.0001.

— (2014). Comisarios y capellanes en la Guerra Civil espańola, 1936-1939. Una mirada comparativa. Ayer, 94, 175-199.

Martín Vigil, J. L. (1977). Las flechas de mi haz. Un hombre, una memoria: Oviedo, Richard Grandio.

Molinero, C. (2006). La captación de las masas. Politica social y propaganda en el régimen franquista. Barcelona: Cátedra.

Morente, F. (2001). La muerte de una ilusión. El magisterio español en la Guerra Civil y el primer franquismo. Historia y Comunicación Social, 6, 187-201.

Núñez de Prado y Clavell, S. (1989). Los partes de guerra franquistas como arma de propaganda en la guerra civil española. Revista de Ciencias de la Información, 6, 211-222.

- (1992). Servicios de información y propaganda en la guerra civil española. 1936-1939 [tesis doctoral]. Universidad Complutense de Madrid.

Paz Fernández, M. A. (1973). Diario de la Campaña (1936-1939). Pontevedra: Taller Tip. E. Paredes.

Pizarroso Quintero, A. (2005). La guerra civil española, un hito en la historia de la propaganda. El Argonauta Español, 2. Disponible en: https://doi.org/10.4000/argonauta. 1195.

- , y Sapag, P. (2012). Propaganda y diplomacia. Proyección exterior de la España franquista (1936-1945). En A. C. Moreno Cantano (coord.). Propagandistas y diplomáticos al servicio de Franco (1936-1945) (pp. 21-54). Gijón: Ediciones Trea.

Rodrigo, J. (2005). Cautivos: Campos de concentración en la España franquista, 1936-1947. Madrid: Crítica. 
- (2009). Presentación. Retaguardia: un espacio de transformación. Ayer, 76, 13-36. (2013). Cruzada, paz, memoria. La Guerra Civil en sus relatos. Granada: Comares.

Rodríguez Barreira, Ó. (2012). Lazarillos del Caudillo. El hurto como arma de los débiles frente a la autarquía. Historia Social, 72, 65-87.

- (2013). Cambalaches. Hambre, moralidad popular y mercados negros de guerra y posguerra. Historia Social, 77, 149-174.

- (2014). The Many Heads of the Hydra: Local Parafascism in Spain and Europe, 193650. Journal of Contemporary History, 49 (4), 702-726. Disponible en: https://doi. org/10.1177/0022009414538476.

Sanz, J. (2004). FET-JONS en Cantabria y el papel del partido único en la dictadura franquista. Ayer, 54, 281-303.

Seidman, M. y Ferrandis Garrayo, M. L. (1997). Frentes en calma de la guerra civil, Historia Social, 27, 37-59.

Villalba Diéguez, F. (1956). Diario de guerra (1938-1939). Madrid: Afrodisio Aguado.

Vincent, M. (2006). La reafirmación de la masculinidad en la cruzada franquista. Cuadernos de Historia Contemporánea, 28 (2006), 135-151

Wright, S. (2016). Los mutilados de Franco: el Benemérito Cuerpo y la política social en la España franquista. Revista Universitaria de Historia Militar, 5 (9), 75-92. Disponible en http://ruhm.es/index.php/RUHM/article/view/156.

Yoshiaki, Y. (2015). Grassroots Fascism. The War Experience of the Japanese People, ed. original en japonés de 1987. New York: Columbia University Press. Disponible en: https://doi. $\operatorname{org} / 10.7312 /$ yosh 16584 . 